\title{
Tarihçilerin Kutbu \\ Halil Hoca'nın Ardından
}

\author{
Akşin Somel*
}

Höchstes Glück der Erdenkinder sei nur die Persönlichkeit Insanoğlu için olabilecek en büyük saadet ancak şahsiyettir

(Goethe)

Kutbül-müverrihîn, günümüz Türkçesiyle tarihçilerin kutbu, Halil Hoca ile ilk karşılaşmam 1993 yılının Nisan ayına rastgelmişti. O zaman Almanya’dan yeni dönmüş, Bilkent Üniversitesi Uluslararası İlişkiler Bölümü’ne yeni girmiş tecrübesiz bir öğretim görevlisiydim. Osmanlı tarihçiliğinde gerçek bir kutup yıldızı olan Halil İnalcık'ın benimle görüşmek istediğini duyduğumda şaşırmışım; benim gibi çiçeği burnunda bir doktoralıyla ne görüşeceğini doğrusu kestiremiyordum. Kendisiyle İktisadi ve İdari Bilimler Fakültesi'nin bir odasında biraraya geldiğimizde önce benden kariyerim hakkında bilgi aldı, sonra tarihsel ilgilerimi ve geleceğe yönelik araştırma projelerimi sordu. Söylediklerimi dikkatle dinledi, biraz düşündükten sonra hiç ummayacağım bir teklifte bulundu; "tarih bölümünü birlikte kuralım mı?” diye sordu. Kendisi Osmanlı kuruluş ve klâsik döneminden, ben ise ondokuzuncu yüzyıl devresinden sorumlu olmak üzere ikili bir yapı oluşturacak, iş birliği yapacaktık. İnalcık gibi dünya çapında bir otoritenin bu teklifini büyük bir heyecanla kabul ettim. Halil Hoca Tarih Bölümü başkanı olacak, ben de ona yardımcı olacaktım.

* Sabancı Üniversitesi. Bu yazının müsveddesini inceleyerek geliştirilmesinde yardımcı olan Sayın Senail Özkan'a ve Tezer Somel'e çok teşekkür ediyorum. 
Hoca o zaman 77 yaşındaydı; University of Chicago'dan emekli olduktan bir süre sonra Bilkent Üniversitesi'nin kurucusu İhsan Doğramacı, Hoca’yı Türkiye'ye davet etmiş, üniversitesinde uluslararası bir Tarih Bölümü’nün kurulması hususunda yardım istemişti. İnalcık bu daveti kabul etmiş, Chicago'daki evini büyük ölçüde tasfiye ederek birçoğu nadir eserlerden oluşan on binlerce ciltten müteşekkil kütüphanesini de Ankara’ya nakletmiş̧i. Söz konusu kütüphane transferi hususunda Halil Hoca’nın bir şartı vardı; Bilkent Kütüphanesi dahilinde kitap koleksiyonuna ayrı bir kısım tahsis edilmesini istiyordu. Bu koşul kabul edilmiş ve üniversite kütüphanesi içerisinde itinayla yalıtılmış, özel soğutucular tarafından havasının nem ve ısı ayarları milimi milimine sabit tutulan bir Inalczk Collection tesis edilmiştir. Sözü geçen koleksiyon, Bilkent Tarih Bölümü hocaları ve doktora öğrencilerinin yanı sıra ilgilenen her araştırmacının istifadesine sunulmuştur. Halen de Ankara ve hatta Türkiye çapında dikkate değer bir araştırma kütüphanesi işlevi de görmektedir.

Bilkent Tarih Bölümü’nün kuruluş sürecine geri dönecek olursak; bölüm resmen kurulduğunda doğal olarak İnalcık'ın bölüm başkanı olmasını bekliyordum. Ancak kurallar gereği yaş haddi nedeniyle Halil Hoca’nın böyle bir görevi üstlenmesinin olanaksız olduğu ortaya çıkınca bu görev ister istemez bana düştü. Altı yıl boyunca bu görevi vekâleten yürütürken kendisiyle etkin bir biçimde teşrik-i mesaimiz oldu. Özellikle ifade etmek isterim ki bu süre zarfındaki yoğun işbirliğimiz süresince kendisi benim için emsalsiz bir akademik örnek teşkil etmiştir. Eğitim yaşamımda bana hocalık yapmamış olmasına karşın bu ortak mesai boyunca kendisinden ve hayat tecrübelerinden öğrendiklerimin değeri her türlü tasavvurun ötesindedir.

Halil İnalcık bir muhacir ailesinin çocuğuydu. Babası Kırım Tatarı, annesi Çerkes kökenliydi. Doğduğu yıl Harb-1 Umumi’nin henüz devam ettiği, Osmanl. İmparatorluğu'nun Almanya ve Avusturya-Macaristan safinda dört cephede çarpıştığı dağdağalı bir zamana denk düşüyordu. Cumhuriyet'in ilk yıllarında ailesi Ankara'ya yerleşti. Babası uzaklarda olduğundan İnalcık’ annesi büyüttü. Gençliğinde çeşitli yaramazlıklar yaptığını, - bir gün evden kaçışı ve annesinin onu Hergele Meydanı'nda kabadayılarla güreşirken yakalaması gibi - zaptedilmesi güç bir çocuk olduğunu ve daha başka gençlik hatıralarını şen kahkahalarla bir sonbahar akşamı kampüs lojmanının balkonunda birlikte çay içerken nakletmişti. Gazi Mustafa Kemal Ankarası'nın inkılapçı ikliminde yetişen İnalcık’ın gençlik 
formasyonu Cumhuriyet'in yeni kurulduğu, Tek Parti rejiminin otoriterliğinin hissedildiği bir çağa aittir.

Bu çerçevede Halil Hoca’nın canlı bir Atatürk hatırasını aktarmak istiyorum. İnalcık, Ulus'daki Gazi İlk Mektebinde öğrenci iken ders esnasında aniden sınıfın kapısı açlır, içeriye resmi görevliler, bir köpek - herhalde Atatürk'ün Fox adlı köpeğiydi - ve ardından da Mustafa Kemal girer. Anlaşılan bu sürpriz bir teftiş ziyaretidir. O sırada tarih dersi işlenmektedir ve duvarda kocaman bir Arabistan yarımadası haritası asılıdır. Halil, sınıfın kısa boylularından olduğundan en ön sırada oturan öğrencilerden birisidir. Gazi Paşa, doğrudan karşısında gördüğü Halil'e yönelerek sorular sormaya başlar. Önce, hangi bahsi öğrendiklerini sorar. Halil, İslamiyetin ortaya çıkışını işlediklerini söyler. Bu cevap üzerine Reisicumhur, İslamiyetin nereden geldiğini sorar. Halil de Arabistan yanıtını verir. Bunu duyan Mustafa Kemal, Halil'e Arabistan nasil bir yerdir diye sual eder. Tam da bir iki gün önce dersin öğretmeni sınıfta çocuklara Arabistan'ın büyük bir yarımada olduğu, kenarlarında sıradağlar bulunduğu, içerlek bölgelerinin ise tepsi gibi düz olduğunu anlatmıştır. Atatürk'ün sorusu üzerine Halil bir an şaşalar, sonra karşıki duvarda Arabistan yarımadasını görünce hocasının söylediklerini hatırlar ve büyük bir coşkuyla "bir tepsi gibidir!" diye haykırmaz mı?

Bu ve buna benzer deneyim ve anıların İnalcık'ta kuvvetli bir Atatürkçü kişilik ve zihin formasyonu yarattığına kuşku yoktur. Öte yandan gerek aile, gerekse eğitim ortamında düşünsel birikimini zenginleştirecek nitelikte farklı kültürel çevrelere mensup dikkate değer kişiliklerle karşılaşmış, söz konusu kişiliklerin doğrudan veya dolaylı etkileri İnalcık'ın entelektüel ufkunu ve eleştirel zihnini genişletmesinde faydalı olmuştur. Halil Hoca’nın anlattığına göre aile dostlarından birisi Ahmet Caferoğlu imiş. Bilindiği gibi Caferoğlu erken Cumhuriyet Türkiyesi'nin önde gelen Türkologlarından ve Azerbaycan kökenli Türkçü aydınlarındandı. Zamanın Türkçü-Turancı akımında önemli bir yeri vardı. Yine Rusya'dan göç etmiş bir Tatar devlet adamı olan Sadri Maksudi Arsal ve ailesi İnalcık'ın Batı kültürüyle tanışmasında etkili olmuştur. Genç İnalcık'ın yine aile çevresinden olan ve fakat Caferoğlu ve Sadri Maksudi'nin belki de tam zıddı diyebileceğimiz diğer bir şahsiyet Eşref Edip Fergan imiş. 2. Meşrutiyet ve erken Cumhuriyet devirlerinin tanınmış İslamcıları arasında bulunan Eşref Edip, 19081925 yılları arasında Sırat-ı Müstakim ve Sebilürreşad dergilerinin editörlerinden biriydi. İlkeli dinî duruşu ve muhafazakârllğı nedeniyle Tek Parti rejiminde köşesine çekilmek zorunda kalmış; ancak koşulların değişmesiyle 1948'de yeniden 
Sebilürreşad 1 yayınlamaya başlamıştır. İnalcık lise öğrenimini Balıkesir İlk Öğretmen Okulu'nda görmüş̧ü. Buradaki hocalarından birisi Abdülbaki Gölpınarlı imiş. Halil Hoca, Gölpınarlı'nın da etkisiyle Osmanlı vakayinamelerini ve Evliya Çelebi seyahatnamesini okumaya başladığından söz ederdi. Bir edebiyat öğretmeni olarak Gölpınarlı’nın İnalcık’a klâsik Osmanlı kültürü ve tasavvuf düşüncesi konularında kuvvetli bir tesir yaptığını söyleyebiliriz.

Halil Hoca, o sıralarda yeni açılmış olan Dil ve Tarih-Coğrafya Fakültesi'ne girdiğinde ilk başta Sinoloji ile ilgilendiğini, bir Sinolog olmak istediğini belirtir. Ne var ki çok sayıda Çince ideogramı ezberlemek kolay değildir; öte yandan Osmanlı tarihinin doğru dürüst araştırılmamış olması onu Osmanlı araştırmalarına yöneltecektir. Esasında İnalcık’n Sinoloji gibi Akdeniz coğrafyasından uzak bir sahayla ilgilenmiş olması başı başına ilginç bir olgudur; Halil Hoca’nın daha çok gençken bile dünya tarihine merakını ve entelektüel alakalarının genişliğini göstermektedir.

İnalcık, tarih lisansını Dil ve Tarih-Coğrafya Fakültesi'nde tamamladıktan sonra buraya asistan olarak girmiş ve tarih doktorasını da aynı fakültede vermiştir. İlginçtir ki Halil Hoca’nın Osmanlı araştırmalarına adım atışı, tarihçilik dünyasına kalıcı damgasını vurduğu Fatih çağı ve Osmanlı klâsik devri gibi konulardan değil, bilakis ondokuzuncu yüzyıl Tanzimat modernleşmesi üzerinden olmuştur. Yayınlanan ilk akademik makaleleri doğrudan Tanzimat hakkındadır. Tanzimat ve Bulgar Meselesi başlıklı doktora tezi ilk önemli eseridir ve 1941'de basıldığında geniş yankılar uyandırmıştır. Bu çalışması, ilk defa Osmanlı tarihçiliğinde köylü ve toprak meselesi konusuna etraflıca değinilmesi ve üstelik de gayri Müslim Sırp ve Bulgar köylülügünün Niş ve Vidin'deki gospodarlar tarafından tâbi tutuldukları haksızlıkların sebep olduğu siyasi patlamalara ışık tutması açısından öncü nitelikte bir araştırmadır. İnalcık'ın bana anlattığına göre doktora tezi yayınlandığında o zamanın Bulgaristan Büyükelçiliği'nden diplomatlar fakülteye gelerek söz konusu incelemesi kapsamında kendisiyle görüşmek istemişlerdi.

Balkanlardaki toprak rejimi ve köylü sorunu İnalcık’ öylesine cezbetmiştir ki meselenin künhüne vâkıf olabilmek amacıyla yüzyıllar ötesine yönelerek Rumeli fütuhatı dönemindeki toprak düzeni üzerinde çalışmaya başlamıştır. Bu ise hocamızı Osmanlı devlet yapısı ve idari düzeninin şekillenme sürecini incelemeye yöneltmiştir. İşte İnalcık’ dünya çapında bir Osmanlı tarihçisi kılan "Timariots chrétiens en Albanie", "Stefan Duşan'dan Osmanlı İmparatorluğu’na”, "Ottoman methods of conquest", "Osmanlılarda Raiyyet Rusûmu", "Centralization and 
Decentralization", "Military and Fiscal Transformation" gibi makaleleri ve Suret-i Defter-i Sancak-ı Arvanid ve Fatih Devri Üzerine Tetkikler ve Vesikalar gibi şaheserleri bu bağlamda mütalaa etmek doğru olacaktır. İnalcık Hoca, ileriki yıllarda çok çeşitli tarih konularında eserler üretmesine rağmen, toprak ve köylü meselesine olan ilgisini hayatının sonuna değin sürdürmüştür. Örneğin 1995 sonrasında gerçekleşmesi için hayli didindiği önemli bir proje, Tanzimat'ın ilk yıllarına ait olup kırsal nüfusun mülkiyet yapısının ve mali gelirlerinin ayrıntısıyla kayıtlı bulunduğu Temettüat Defterleri'nin bilgisayar programları yardımıyla mufassal bir veri tabanına dönüştürülmesi girişimiydi.

Doktora tezinden başlayarak 1950 'li ve 60 'lı yıllarda Halil Hoca’nın çağdaşı olan bir çok diğer Türkiyeli tarihçi arasında temayüz etmesini sağlayan iki husus bilhassa önemlidir. Birincisi, tarihi belgeleri olduğu gibi kabul etmek yerine kritik bir akılla tahlil ederek vesikaların ardında yatan etkenleri ortaya çıkarma gayreti. İkincisi, yabancı literatürü mümkün mertebe yakından takip ederek tarihçilik alanında gerçekleşen uluslararası yenilikleri kavramaktı. İnalcık'ın birinci yabancı dili Fransızcaydı ve pek çok uluslararası yayını Fransızca versiyonundan takip ediyordu. Ancak bunun yanısıra araştırma literatürünü okuyacak düzeyde Almanca da öğrenmişti. Projeleri açısından önem arzeden Bulgarca, Sırpça, Rusça makaleleri ve kitapları mümkün mertebe tercüme ettiriyordu. Yine bu devrede öğrendiği İngilizce, Chicago Ünivesitesi'ndeki hocalığı esnasında mükemmel bir seviyeye erişmişti.

Halil Hoca'nın Osmanlı tarihi, Balkan incelemeleri ve Ortadoğu araştırmaları alanında uluslararası isim ve çevrelerle yakın ilişkiler kurduğu ve bu ilişkilerin dar mesleki sınırları aşarak kuvvetli bir insanî boyut kazandığı da vurgulanmalıdır. Bu bağlamda Paul Wittek, Bernard Lewis ve Fernard Braudel gibi isimler zikredilebilir. Balkan incelemelerinde Nedim Filipović, Olga Zirojević, Duțanka Bojanić, Nikolay Todorov, Vera Mutafçieva, Evgeniy Raduțev gibi isimler belirtilmelidir. İnsanlık suçlarından mahkûm Sırp lider Slobodan Miloțević’in Yugoslavya’yı NATO ile savaşa sürüklediği dönemde İnalcık Hoca yokluk ve s1kıntı içinde sürünen bazı Yugoslav meslektaşlarına maddi destek vermiş, hatta bazılarını lojmanında bir müddet ağırlayacak derecede insaniyet sergilemiştir.

Öte yandan bilimsel açıdan o zamana değin egemen olan görüş ve anlayışlara cesaretle karşı çıktığını ve bundan ötürü bazı uluslararası tarihçilerle de çatıştı̆̆ını biliyoruz. Halil Hoca’nın bu konuda bana naklettiği canlı bir hatırası da Bavyeralı şarkiyatçı Franz Babinger'le ilgilidir. Bilindiği üzere Babinger Fatih 
Sultan Mehmed'i konu alan Mehmed der Eroberer und seine Zeit ("Fatih Sultan Mehmed ve Zamanı") başlıklı eserini 1953'de yayınlanmıştı. Büyük ölçüde Venedik kaynaklarına dayanarak yazılmış bu çalışmada Babinger, Fatih'i zalim, gaddar ve hatta sadist bir hükümdar olarak betimlemişti. Söz konusu eserin basımından bir sene sonra İnalcık Osmanlı kaynaklarına dayanarak yayınladığı Fatih Devri Üzerine Tetkikler ve Vesikalar başlıklı araştırmasında Babinger'in Fatih ile ilgili iddialarını belgesel kanıtlarla çürütmüştü. Ayrıca bir Amerikan akademik tarih yayınında Babinger'in eserindeki bazı kronolojik hataları ortaya koymuştu. Bu eleştirileri hazmedemeyen Babinger'in kıpkırmızı yüzü ve iri kıyım cüssesiyle şarkiyat kongrelerinde "İnalcık nerede?” diye kendisini hiddetle aradığını gülerek anlatırdı.

Halil İnalcık'ın akademik yaşamı, 1972'de Ankara Üniversitesi'nden emekli olup Chicago Üniversitesi Tarih Bölümü’ne geçmesiyle yeni bir merhaleye girmiştir. Bu dönemde İnalcık artık uluslararası akademik camianın ayrılmaz bir parçası olmuştur. Halil Hoca’nın söz konusu devrede Osmanlı tarihçiliğine yaptığı en büyük katkılardan birisi o zamanlara değin İslam Tarihi ve Ortadoğu araştırmaları bünyesinde marjinal bir konumda bulunan Osmanlı araştırmaları sahasına disipliner bağımsızlık ve itibar kazandırmak ve küresel anlamda Osmanlı Tarihi'ni kendi başına egemen ve özgün bir araştırma dalı olarak kabul ettirmek oldu.

İnalcık'in tâ 1940 'lardan beri artan bir ilgiyle takip ettiği köy ve toprak konusu hiç şüphesiz ona mezkûr başarıyı kazandıran önemli etkenlerden birisidir. Mevzu bahis ilgi, tam da Soğuk Savaş döneminde dünyadaki pek çok entelektüel arasında güçlenen çeşitli Sol akımlar ve bu çerçevede sosyal ve ekonomik tarihçiliğe artan temayüllerle kayda değer bir uyum arz ediyordu. Bildiğim kadarıyla İnalcık hiç bir zaman Solcu olmamıştır; aksine, siyasi anlamıyla Marksizme karşıtlığını sıkça ifade etmiştir. Esasında İnalcık, gençlik formasyonunun temelini teşkil eden Türk milliyetçiliği ve devlete bağlılık çizgisinden pek kopmamıştır. Öte yandan kritik aklı ve engin entelektüel birikiminin Halil Hoca’ya sağladığı evrensel ufuk, onu her türlü siyasal ve akademik bağnazlıktan kurtarmıştır. Özünde hiç de hoşlanmadığı Marksizmi ve Marksist tarihsel yaklaşımları nispeten geç bir yaşta incelemiş ve Chayanof'un tarımsal üretim kuramlarından da esinlenerek köylülük, toprak meselesi ve klâsik dönem Osmanlı üretim tarzına dair "Çift-Hane" birimi gibi özgün kuramsal bir model önermiştir ki bu model günümüzde dünya tarihçiler câmiasınca büyük ölçüde kabul görmektedir. 
Halil Hoca ömrünün son aylarına değin çalışmaktan, araştırmaktan ve üretmekten geri durmamıştır. Öyle ki son yıllarında telif ettiği eserleri yeni baskılar halinde kitapçı raflarında yerini almakta ve çok satanlar arasında bulunmaktadır. Kendisini 2015 sonlarında ziyaret ettiğimde bana yığınla üst üste birikmiş dosya kümelerini göstererek yakın gelecekte kaleme alacağı makale ve kitap projelerinden bahsetmişti. Üretken olmaya çok önem veren İnalcık'in zihnime nakş olmuş çarpıcı bir insan ömrü benzetmesi şudur: ona göre kişi ömrü bir resim tablosuna benzer. Tabloda neyin nerede bulunması gerektiği veya hangi konuların hangi zenginlikte, incelikte veya yalınlıkta tasvir edildiği, ayrıca kullanılan malzemenin niteliği, yani kalem, pastel, suluboya veya yağlıboya mı yoksa bunların bileşiminin mi kullanıldığı söz konusu ömrün nasıl geçmiş olduğunun bir yansıması gibidir. Anladığım kadarıyla Halil Hoca kendi hayatına da bu perspektiften bakmaktaydı; vefat ettiğinde arkasında nitelikli ve kalıcı yapıtlar bırakmak kaygısını ruhunda barındırmaktaydı. Umarım burada sözünü etmiş olduğum birikmiş kıymetli proje malzemelerine öğrencileri ve yakınları sahip çıkar ve bu değerli birikim kaybolup gitmez.

Yaşama inanılmaz derecede bağlıydı; son zamanlara kadar lojmanında kendisinden yetmiş beş-seksen yaş küçük olan gençlere, yüksek lisans öğrencilerine seminerler vermekteydi. Burada güttüğü amaç genç kuşaklarla yakın temas içinde kalmak; onların nasıl düşündüklerini; neler hissettiklerini öğrenmek ve böylelikle de Türkiye'nin geleceği hakkında tahminler yapabilmekti. Kendisine aykırı düşünce ve görüşleri öğrenmeye ve anlamaya gayret ederdi. 1990’lı yıllarda Kürt sorununun tartışılmasının henüz hassas kabul edildiği ve terörün tırmandığı bir devrede İnalcık'ın lojmanında teröre destek veren gazeteler gördügümde hayli şaşırdığımı hatırlıyorum; şaşkınlığımı gören Halil Hoca söz konusu yayınların Türk siyasal yaşamında olumsuz da olsa belirli bir durumu yansıttığını ve dolayısıyla hakkında bilgi edinilmesi gerektiğini vurgulamıştı. Halil Hoca’nın hiç unutamadığım ve bana her zaman ders niteliğinde olacak bir sözü de şuydu: "Akşinciğim, hepimiz öğrenciyiz."

İnalcık'nn kişiliği ile ilgili olarak halen gözümün önünde kalmıs bir diğer niteliği ruhunun derinliklerinde barındırdığı tevazuydu. Kendisi bir muhacir çocuğu olarak çok da rahat koşullarda yetişmemişti. 1950’li yıllardan başlayarak akademik câmiada yıldızı parlamaya başlamış, 1970'lerle birlikte dünyanın en seçkin tarihçilerinden birisi konumuna erişmişti. Böylesi bir akademik şöhretle paralel olarak özellikle ileri yaşlarında dünyanın her tarafından dört başı mamur 
profesörler kendisini ziyarete gelmekte, uluslararası bir kongre için yurt dışına gittiğinde oranın basını bir röportaj koparabilmek için etrafında adeta pervane olmakta, başta Cumhurbaşkanı olmak üzere Türk siyasetçileri görüş almak üzere onunla temas kurabildiklerinde bunu bir ayrıcalık olarak algılamaktaydılar. Sözünü ettiğim bu tarifi güç ilgi yoğunluğuna karşın en azından kendisini tanıdığım yıllardaki Halil Hoca dış görünüş itibarıyla kalender meşrep, duruşu itibarıyla hafif çekingen, kendisiyle tanışmak isteyen kimseyi reddetmeyen, davranışlarında kibir izi görülmeyen bir şahsiyetti. Birilerini eleştireceği veya karşı çıkacağı zaman bunu güler yüzlülükle, bazen ince bir istihza ile gerçekleştirirdi. Hocanın bu özelliğiyle ilgili olarak bir anım şudur: İnalcık için son yıllarda Bilkent Oteli’nde düzenlenen kalabalık doğum günü partilerinden birisinde tanınmış bir şair Halil Hoca şerefine düzmüş olduğu bir kasideyi coşkuyla okumuştu. Kaside Hoca’yı tarihin gelmiş geçmiş en büyük tarihçisi olarak nitelendirmekte, eserlerinin hakikati, doğruluğu, güzelliği, erdemi vs. vs. içerdiğini vurgulamaktaydı. Şair eserini hevesle okurken "İnalcık en güzel yazar, en güzel yorumlar, en güzel öğretir, en güzel vs. vs." derken Hoca araya atılıp "ama mübalağa etmez" demez mi?

İkinci bir Halil İnalcık veya Halil İnalcık benzeri bir akademik kişiliğin bundan böyle artık dünyaya geleceğini pek sanmıyorum. İnalcık Hoca’nın Osmanlı tarihçiliğindeki ihatasına benzer bir akademik fenomenin ortaya çıkması çok zor gibi görünüyor. İnalcık' 'n yetiştiği zamanlarda Osmanlı tarihine ilişkin araştırma literatürü sınırlı olup konu ve yüzyıl bazında bir uzmanlaşma henüz pek gelişmemişti. Buna ilaveten 1930'lar öncesinde Osmanlı devlet arşivlerini akademik câmiaya açmak doğrultusunda herhangi bir resmî çaba söz konusu değildi. Halil Hoca’nın 1937 sonrasında çağdaş anlamda tasnif sürecine giren Osmanlı arşivlerini kullanmaya başlayan ilk tarihçi kuşağından olduğu söylenebilir. Unutulmamalıdır ki modern Osmanlı tarihçiliğinin kurucuları olarak kabul edilen Fuat Köprülü, Ömer Lutfi Barkan ve İsmail Hakkı Uzunçarşılı ilk araştırmalarında devletin merkez arşivlerinden ziyade vakıf arşivleri ve eski kütüphaneleri kullanmak durumundaydılar. Dolayısıyla genç akademisyen İnalcık açısından Osmanlı tarihçiliği neredeyse her alanda ciddi boşluklarla malûldü. Böylesi koşullarda İnalcık günümüz tarihçiliğinde egemen olan uzmanlaşma baskısından azade olarak neredeyse her konuda orijinal araştırma yapabilme özgürlüğüne sahip olmuştur.

Halil Hoca’yı daha sonraki Osmanistlerden ayırt eden kritik bir özellik Osmanlı yazılı edebiyat ve kültürünü son demlerinde yakalayabilmiş olmasıdır. Harf İnkılâbı öncesinde eski yazıyı akıcı bir şekilde okuyup yazmayı öğrenmiş olan 
İnalcık, Balıkesir'de hocası olan Abdülbaki Gölpınarlı'dan klâsik Osmanlı literatürünü okumuştu. Bu tarz bir kültür altyapısı kendisine Osmanlı kaynaklarına rahatlıkla ve derinlemesine nüfuz etme olanağını sağlamıştır. Yirminci yüzyıl ortalarında ve sonrasında yetişen bir Osmanlı tarihçisinin mevzu bahis kültür altyapısına ve derinliğine - tüm dil becerilerine ve kişisel gayretine rağmen - erişebilmesi pek mümkün gözükmüyor.

Tarih disiplininde akademik verimin ve üretkenliğin, bilgi ve tecrübe birikiminin olgunluk seviyesine eriştiği yaşlılık çağında olduğu söylenebilir. Bu açıdan Halil Hoca’nın vefatı sadece insanî değil, özellikle bilimsel bakımdan da çok ağır ve yerine konulması mümkün olmayan bir kayıptır. Aziz dostum Halil İnalcık’ gerek tarihçi, gerekse insanî kişiliğiyle tanımış olmak benim için ömür boyu sürecek bir ayrıcalık olacaktır. 